\title{
PERBANDINGAN EFEKTIFITAS MEDIA BIOFILTER PECAHAN GENTENG DAN BIOBALL DALAM MENURUNKAN KADAR DETERJEN LIMBAH LAUNDRY
}

\author{
Astrid Retno Hapsari, Hadi Suryono, Pratiwi Hermiyanti
}

\begin{abstract}
Continuous direct discharge of untreated laundry effluent into the streams may cause problems of water pollution and harm to human health. Treatment with biofilter is one chosen among the treatments for the effluent. It had the purpose of comparing the effectiveness of broken roof tiles and bioball as biofilter media in reducing the detergent levels of laundry effluent after aerobic treatment.

The study was an analytic experiment using the one-group pretest-posttest design. Methods of analysis to test the differences in the effeciency of reducing detergent levels between broken roof tiles and bioball as biofilter media combined with activated carbon using statistical test Independent Sample $T$ Test. The parameter to be measured was detergent level by the use of Metylena Blue Active Subtances (MBAs) method.

Results showed that the bioball biofilter reactor modified with activated carbon had the largest decrease in the level of detergent in the laundry effluent with efficiency of $1.61 \%$ after 160 minutes of flowing. Statistical tests showed that, $p=0,063$ so $p$ (sig) $>0,05$ there was no significant difference in the efficiency of reducing detergent levels for both biofilter media.

Both biofilter media were not effective in reducing the levels of detergent since the effluent remained above the standard value. Utilization of biofilter technology requires a pre-treatment stage, such as coagulation-flocculation due to high levels of pollutants, in order to prevent effluent from polluting surfaces water. In addition, further studies are required which use the acclimatization process and different contact time and biofilter media as well as examining other parameters.
\end{abstract}

Keywords : Biofilter, Bioball, Broken Roof Tiles, Detergent Levels, Effluent of Laundry

\section{PENDAHULUAN}

Seiring dengan perkembangan ekonomi yang pesat, masyarakat memilih menyelesaikan kegiatan rumah secara praktis seperti pencucian baju dan diserahkan kepada laundry. Dampak yang ditimbulkan bila air bekas kegiatan laundry langsung dibuang ke badan air atau lingkungan secara terus menerus tanpa ada proses pengolahan terlebih dahulu dapat menimbulkan masalah pencemaran air dan menggaggu kesehatan manusia yang menggunakan baku air tersebut.

Dua bahan terpenting dari pembentuk deterjen yakni surfaktan dan builder (Padmaningrum, R.T., dkk, 2014). Di Indonesia pada umumnya menggunkan builder jenis Phosphat. Phosphat berasal dari Sodium TriPoly Phosphate (STPP) yang merupakan bahan builder yang sangat penting setelah surfaktan. STPP berfungsi untuk menghilangkan mineral kesadahan dalam air sehingga deterjen dapat bekerja optimal (Dewi, F., dkk, 2015).

Pemukiman sekitar instansi pendidikan seperti di daerah Pucang Jajar yang berada di area Poltekkes Kemenkes Surabaya diketahui merupakan rumah kos mahasiswa. Sehingga tidak dapat dipungkiri didaerah tersebut banyak terdapat usaha rumah tangga laundry. Limbah cair laundry yang dihasilkan oleh usaha rumah tangga umumnya langsung dibuang ke badan air tanpa adanya pengolahan terlebih dahulu.

Salah satu pengolahan yang dapat dilakukan untuk menurunkan kadar deterjen adalah pengolahan dengan biofilter. Media biofilter yang digunakan adalah pecahan genteng dan bioball. Tujuan penelitian ini adalah untuk membandingkan efektifitas paduan media biofilter yang efektif dalam menurunkan kadar deterjen dalam limbah cair laundry.

\section{METODE PENELITIAN}

Jenis penelitian yang akan dilakukan oleh peneliti adalah analitik eksperimental dengan desain penelitian adalah one group pretest posttest design untuk mengetahui pengaruh yang ditimbulkan akibat adanya suatu percobaan.

Sampel air limbah laundry diambil dari laundry X di daerah Manyar Dukuh, Surabaya baik sebelum dan sesudah diolah dengan menggunakan media biofilter yang dipadukan karbon aktif. 
Untuk menguji perbedaan efisiensi penurunan kadar deterjen pada media biofilter pecahan genteng dan bioball dipadukan dengan karbon aktif digunakan uji statistik Independent Sample $T$ Test dengan menggunakan program statistik komputer.

\section{HASIL DAN PEMBAHASAN}

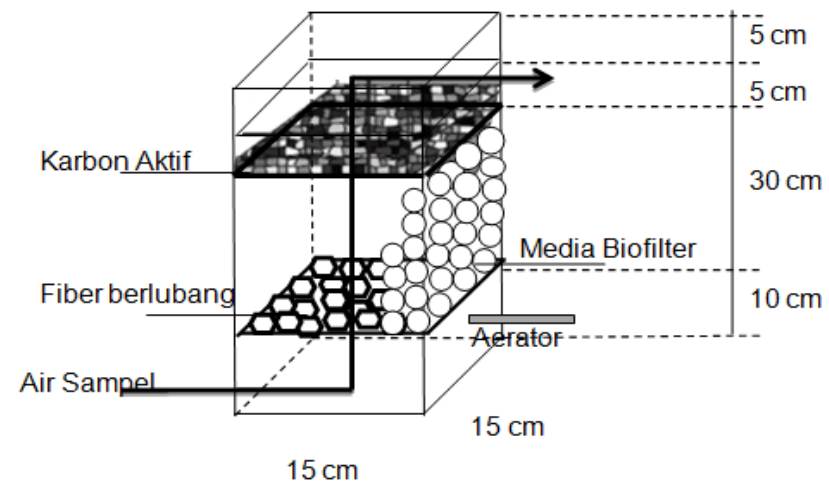

Sumber : Penelitian Bambang Switarto dan Sugito, 2012.

Gambar 1. Rancangan Reaktor Biofilter Aerobik

1. Proses Seeding

a. $\mathrm{pH}$

pH selama proses seeding pada reaktor dengan media biofilter pecahan genteng kombinasi karbon aktif maupun pada media biofilter bioball kombinasi karbon aktif adalah 7. Hal ini sesuai dengan pendapat Muliartha (2004), bahwa pH optimum bagi pertumbuhan bakteri adalah $6,5-7,5$.

b. Suhu

Suhu selama proses seeding pada media biofilter pecahan genteng kombinasi karbon aktif maupun pada media biofilter bioball kombinasi karbon aktif adalah sekitar 29,5 - $30{ }^{\circ} \mathrm{C}$. Hal ini sesuai dengan suhu yang baik untuk bakteri mesofilik yaitu sekitar $25-37{ }^{\circ} \mathrm{C}$ dengan suhu optimum $32{ }^{\circ} \mathrm{C}$. Dalam penelitian Heryani Adhitiastuti dan Puji Hastuti Oktafia Bisono (2008) yaitu golangan bakteri Proteobacteria mendominasi dalam proses pendegradasian kadar deterjen. Bakteri tersebut merupakan bakteri patogen, yang mana semua bakteri patogen termasuk kelompok bakteri mesofilik.

Suhu menjadi turun pada hari ke - 9 dikarenakan cuaca yang mendung dan dingin sedangkan suhu menjadi naik dikarenakan cuaca disekitar cukup panas sehingga mempengaruhi suhu pada media biofilter didalam reaktor.

2. Proses Pengolahan Unit Reaktor Biofilter Aerobik a. Kadar Deterjen pada Limbah Cair Laundry Sebelum dan Sesudah Melewati Kedua Reaktor Boifilter

Tabel 1

Kadar Deterjen pada Limbah Cair Laundry Sebelum dan Sesudah Melewati Kedua Reaktor Biofilter

\begin{tabular}{|c|c|c|c|}
\hline $\begin{array}{c}\text { Sampel } \\
\text { Ke- }\end{array}$ & $\begin{array}{c}\text { Kaciar Deterjen } \\
\text { Sebelum } \\
\text { Pengolahan (mg/l) }\end{array}$ & $\begin{array}{l}\text { Kadar Deterjen } \\
\text { Pengolahan } \\
\text { Pecahan } \\
\text { Genteng }\end{array}$ & $\begin{array}{l}\text { Sesudah } \\
\text { (mg/l) } \\
\text { Bioball }\end{array}$ \\
\hline 1 & 351,28 & 351,07 & 351,17 \\
\hline 2 & 351,28 & 351,04 & 350,51 \\
\hline 3 & 351,28 & 350,89 & 350,02 \\
\hline 4 & 351,28 & 350,72 & 349,62 \\
\hline 5 & 351,28 & 350,44 & 349,23 \\
\hline 6 & 351,28 & 350,33 & 349,08 \\
\hline 7 & 351,28 & 350,08 & 348,71 \\
\hline 8 & 351,28 & 350,04 & 348,22 \\
\hline 9 & 351,28 & 349,59 & 347,69 \\
\hline 10 & 351,28 & 349,21 & 347,47 \\
\hline 11 & 351,28 & 348,61 & 346,84 \\
\hline 12 & 351,28 & 348,10 & 346,65 \\
\hline 13 & 351,28 & 347,47 & 345,96 \\
\hline 14 & 351,28 & 347,16 & 345,85 \\
\hline 15 & 351,28 & 346,51 & 345,64 \\
\hline 16 & 351,28 & 346,05 & 345,32 \\
\hline
\end{tabular}


Berdasarkan tabel 1. menunjukkan bahwa terjadi penurunan kadar deterjen setelah air baku dilewatkan pada reaktor biofilter pecahan genteng modifikasi karbon aktif dan reaktor biofilter bioball modifikasi karbon aktif. Kadar deterjen limbah cair laundry sebelum dilakukan pengolahan adalah $351,28 \mathrm{mg} / \mathrm{l}$. Media biofilter bioball merupakan media biofilter yang terbaik dalam menurunkan kadar deterjen daripada media biofilter pecahan genteng.

a. Efektifitas Penurunan Kadar Deterjen Sesudah Melewati Kedua Biofilter

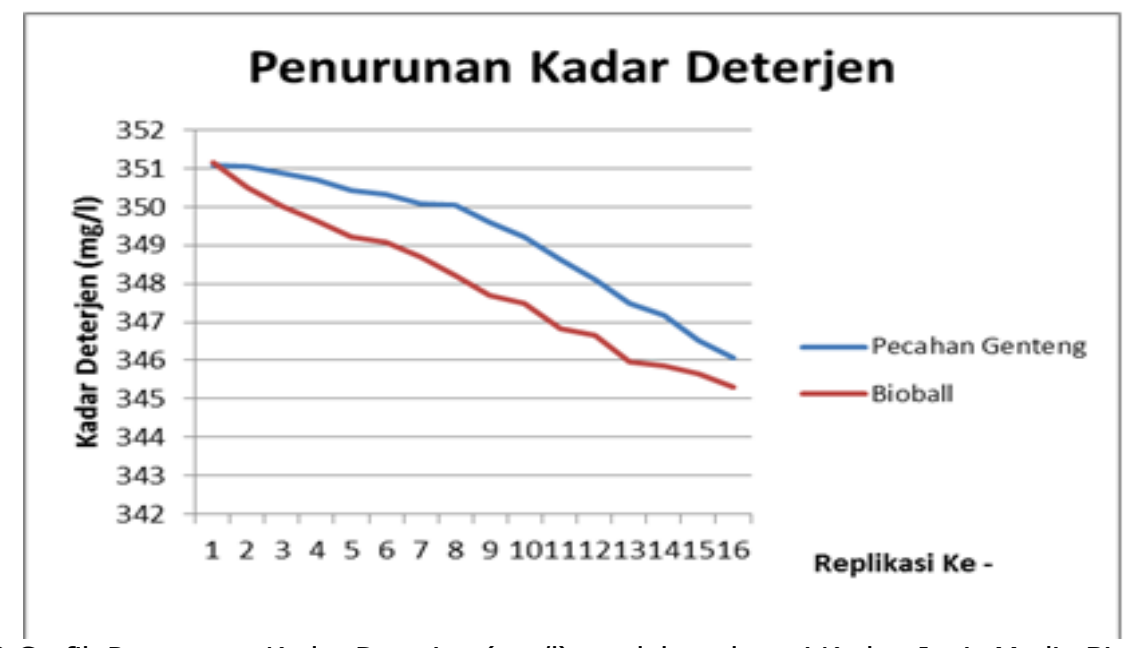

Gambar 2.Grafik Penurunan Kadar Deterjen (mg/l) setelah melewati Kedua Jenis Media Biofilter

Berdasarkan gambar 2. tentang grafik penurunan kadar deterjen $(\mathrm{mg} / \mathrm{l})$ setelah melewati kedua jenis media biofilter, maka kedua jenis media biofilter tersebut tidak efektif dalam penurunan kadar deterjen. Hal tersebut disebabkan hasil effluent yang dihasilkan masih diatas nilai ambang batas yang telah ditentukan dalam Peraturan Gubernur Jawa Timur Nomor 72 Tahun 2013.

Hal tersebut menunjukkan bahwa kedua media biofilter tidak efektif dalam menurunkan kadar deterjen pada limbah laundry. Angka penurunan semakin naik disebabkan pengambilan sampel dilakukan pada saat proses aklimatisasi. Aklimatisasi adalah proses adaptasi mikroorganisme terhadap air buangan yang akan diolah (Said, 2005).

b. Tingkat Efisiensi Penurunan Kadar Deterjen Sesudah Melewati Kedua Reaktor Biofilter

Tabel 2. Tingkat Efisiensi Penurunan Kadar Deterjen Sesudah Melewati Kedua Reaktor Biofilter

Media biofilter bioball memiliki tingkat efisiensi penurunan kadar deterjen tertinggi hingga $1,70 \%$ daripada media biofilter pecahan genteng. Hal tersebut dikarenakan luas permukaan media yang dimiliki bioball lebih besar daripada luas permukaan media pecahan genteng. Menurut Said (2008), semakin luas permukaan maka jumlah bakteri yang tumbuh dan menempel pada permukaan media semakin banyak sehingga efisiensi pengolahan media menjadi lebih besar.
Dari hasil uji Independent Sample T test tingkat efisiensi penurunan kadar deterjen pada kedua media biofilter menunjukkan nilai signifikan untuk tingkat efisiensi penurunan kadar deterjen antara kedua media biofilter yaitu 0,063 sehingga $\mathrm{p}$ (sig) >0,05. Hal ini menunjukkan tidak ada perbedaan tingkat efisiensi penurunan kadar deterjen yang signifikan antara kedua media biofilter.

Secara keseluruhan, unit biofilter aerobik ini dalam menurunkan kadar deterjen pada limbah cair laundry sangat rendah dikarenakan waktu tinggal didalam reaktor yang kurang dan mungkin bakteri yang tumbuh belum optimal. Dalam proses pertumbuhan bakteri agar tumbuh optimal dipengaruhi oleh beberapa faktor antara lain : $\mathrm{pH}$, suhu, waktu tinggal hidrolisis dan nutrien.

Dalam penelitian ini, waktu tinggal didalam reaktor kurang karena pendeknya waktu tinggal dalam reaktor biofilter sehingga perlu penambahan waktu tinggal dengan cara memperkecil debit aliran atau dengan pengontakkan ulang limbah cair didalam reaktor biofilter. Sedangkan untuk nutrien bakteri, dalam penelitian ini tidak dilakukan perhitungan TPC (Total Plate Count) dan kontrol terhadap perbandingan antara karbon, nitrogen dan phospor yang merupakan nutrien anorganik utama yang diperlukan oleh bakteri. Adapun perbandingan jumlah Karbon, Nitrogen dan Phospor 
proses aerobik adalah 100:5:1 (Rakhma Putri, Arifani, dkk, 2012). Penambahan karbon, nitrogen dan phospor dapat dilakukan dengan penambahan pupuk urea atau TSP (Triple Super Phospate) pada air baku.

\section{KESIMPULAN}

Kadar deterjen sebelum dilakukan pengolahan inlet pada masing - masing reaktor biofilter adalah sebesar 351,28 mg/l.Kadar deterjen dalam limbah cair laundry mengalami penurunan setelah melewati reaktor biofilter media pecahan genteng dan bioball modifikasi karbon aktif. Media biofilter pecahan genteng dan bioball modifikasi karbon aktif tidak efektif dalam penurunan kadar deterjen pada limbah cair laundry.

\section{DAFTAR PUSTAKA}

Adhiastuti, Heryani dan Bisono, Puji Hastuti Oktafia. 2008. Pengolahan Limbah Deterjen Sintetik Dengan Trickling Filter. Tugas Akhir. Jurusan Teknik Kimia Fakultas Tenik Universitas Diponegoro.

Fitri, Dewi, dkk. Maret 2015. Efisiensi Penyerapan Phospat Limbah Laundry Menggunakan Kangkung Air (Ipomoea Aquatic Forsk) Dan Jeringau (Acorus Calamus) . Jurnal Teknik Kimia Volume 4 (1): 7 - 10. ISSN: 2337-4888

Muliartha, I Ketut. 2004. Pedoman Teknis Pengelolaan Limbah Cair Industri Kecil. Jakarta: Kementerian Lingkungan Hidup.

Notoadmodjo, Soekidjo. 2012. Metode Penelitian Kesehatan. Jakarta: PT Asdi Mahasatya.

Padmaningrum, R.T dkk. 2014. Pengaruh Biomassa Melati Air (Echinodorus Paleafolius) dan Teratai (Nyphaea Firecrest) Terhadap Kadar Fosfat, BOD, COD, TSS, Dan Derajat Keasaman Limbah Cair Laundry. Jurnal Penelitian Saintek 19 (2): 65 - 74.

Peraturan Gubernur Jawa Timur Nomor 72 Tahun 2013 Tentang Baku Mutu Air

\section{SARAN}

a. Bagi Peneliti

Sebaiknya dilakukan pemeriksaan TPC (Total Plate Coloni), perhitungan C:N:P, penambahan waktu tinggal dalam reaktor. Untuk meningkatkan penurunan kadar deterjen, sebaiknya air baku dilakukan pengolahan terlebih dahulu. Peneliti dapat mengembangkan penelitian terhadap parameter lain dengan variasi media biofilter yang sama. Peneliti selanjutnya dapat menggunakan variasi jenis media biofilter yang lain dalam menurunkan kadar deterjen.

b. Bagi Pemilik Laundry

Sebaiknya pemilik laundry mengolah limbah cair pada tahap pre treatment seperti flokulasi dengan penambahan tawas jenuh sebelum menerapkan biofilter yang digunakan oleh peneliti karena kadar polutan yang sangat tinggi sehingga tidak mencemari badan air.

Limbah Bagi Industri dan/ atau Kegiatan Usaha Lainnya

Tri Suarbawa , I Komang dan Ali, Munawar. 2015. Anaerob Fixed Bed Reaktor Untuk Menurunkan COD, Fosfat (PO4) dan Deterjen (LAS). Jurnal IImiah Teknik Lingkungan 6 (2): 65 - 72. ISSN: 2085-501X

Putri, Arifiani Rakhma, dkk. 2013. Penentuan Rasio BOD/COD Optimal pada Reaktor Aerob, Fakultatif dan Aerob. Jurnal Teknik Lingkungan 2 (1): $1-4$.

Said, Nusa Idaman. 2005. Aplikasi Bio-Ball Untuk Media Biofilter Studi Kasusu Pengolahan Air Limbah Pencucian Jean. Jurnal Air Bersih Indonesia 1 (1): 1 - 11. ISSN: 0216-4140.

Said, Nusa Idaman. 2008. Pengolahan Air Limbah Domestik di DKI Djakarta "Tinjauan Permasalahan, Startegi dan Teknologi Pengolahan". Jakarta: Pusat Teknologi Lingkungan.

Switarto, Bambang dan Sugito. 2012. Aplikasi Biofilter Aeobik Untuk Menurunkan Kandungan Deterjen Pada Air Limbah Laundry. Jurnal Teknik Waktu 1 (2): 23 - 31. ISSN: 1412-1867 